\title{
Os bebês e os espaços da creche: um estudo de caso/intervenção
}

\author{
Babies and the space of day-care center: \\ a case study/intervention
}

Ana Rosa Costa Picanço MOREIRA ${ }^{1}$

\begin{abstract}
Resumo
Este artigo tem o objetivo de discutir a organização espacial de berçários de creche a partir dos significados que os educadores atribuem ao espaço. Trata-se de um estudo de caso/ intervenção realizado numa creche institucional do município do Rio de Janeiro. Parte da perspectiva histórico-cultural e interdisciplinar do espaço concebendo-o como elemento pedagógico, relacional, simbólico e histórico. Participaram do estudo 8 educadores e 24 bebês que frequentavam o Berçári o I. Foram analisadas fotos dos arranjos espaciais, sessóes reflexivas com os educadores e observaçóes realizadas ao longo de 2008. Os resultados indicam que as intervenções feitas através de ações colaborativas de reflexão propiciaram mudanças significativas no modo de organização desse ambiente.
\end{abstract}

Palavras-chave: Organização espacial. Bebês. Creche. Prática pedagógica.
Abstract

This article aims to discuss the spatial organization of day-care nurseries based in the meaning of space created by the educators. This is a case study/intervention conducted in the city of Rio de Janeiro. We start with a cultural-historical and interdisciplinary understanding of space conceiving it as an educational, relational, historical and symbolic. The study included eight educators and 24 babies. We analyzed photos of spatial arrangements, reflective sessions with educators and observations made during 2008. The results indicate that interventions, through collaborative actions with the educators, produced significant changes in the mode of organization that room.

Keywords: Spatial organization. Babies. Daycare Center. Pedagogical practice.

1 Graduada em Psicologia (UFF), mestra em Psicologia Social (UGF) e doutora em Educação (UERJ). Professora Adjunta da Universidade Federal de Juiz de Fora. Membro do Grupo de Pesquisa Linguagem, Educação, Formação de Professores e Infância (LEFoPI) e Grupo de Pesquisa e Estudos em Geografia da Infância (GRUPEGI). Pesquisadora na área de Educaçáo Infantil. Endereço: Universidade Federal de Juiz de Fora, Campus Universitário, Faculdade de Educação. Bairro Martelos. Juiz de Fora. CEP: 36036-330. Tel.: 2102-3655. E-mail: <anarosamaio@uol.com.br>. Apoio FAPERJ.

R. Educ. Públ. v. 22

n. $49 / 1$

p. $305-325$ maio/ago. 2013 


\section{Introdução}

Na sala do Berçário I $60^{2}$, os berços estavam arrumados um
ao lado do outro, formando dois vãos entre eles: um era
acessível às crianças, e outro só era possível de ser alcançado
passando por debaixo de um móvel. Ma e Fif passaram
pelos vãos, como se esses fossem um túneis, indo e voltando
várias vezes e, depois, permaneceram no vão de mais difícil
acesso e começaram a brincar: elas pegaram uma chupeta
e um travesseiro que estavam dentro de um dos berços e
os deram a Va, que se deitou no chão com os dois objetos
como se estivesse num berço, enquanto as duas lhe faziam
carinho no rosto e balançavam o seu corpo, ninando como
as educadoras costumavam fazer. (MOREIRA, nota de
campo de 01 set. 2008)

A nota de campo acima revela como as crianças, desde muito cedo, inventam seus espaços de brincadeira e na brincadeira, mesmo quando os ambientes são organizados pelos adultos para outros fins. Dessa forma, barreiras se transformam em desafios; limites abrem possibilidades de conquistas e espaços proibidos se tornam lugares de resistência, de invenção e de criação. Através dos movimentos e das relaçôes criativas que as crianças estabelecem com os objetos e o mobiliário elas potencializam os ambientes construídos pelos adultos, redesenhando espacialidades outras e se constituindo como sujeitos nesses espaços.

Hoje, cada vez mais cedo, muitos bebês têm a creche como ambiente privilegiado para suas experiências cotidianas. $\mathrm{Na}$ creche, geralmente, eles passam grande parte do tempo convivendo com outras crianças e adultos e interagindo com ambientes que são planejados para uma infância idealizada, abstrata e universal, distante de interesses, manifestaçóes e expressóes de crianças concretas. A preocupação com a adequação dos ambientes ao bebê a partir do ponto de vista só do adulto, sem levar em conta suas linguagens, suas formas de ser e estar no mundo, tem revelado o desconhecimento da riqueza do universo infantil e suas possibilidades.

O debate sobre a questão da organização de ambientes para bebês nas creches ainda é recente. Estudos do campo da Psicologia Ambiental,

2 Agrupamento de crianças de quatro a 11 meses estabelecido e nomeado de acordo com a Portaria E/ DGED no 20 de 18 de novembro de 2003. 
utilizando metodologia semi-experimental, foram precursores em descrever os efeitos da organizaçáo espacial dos ambientes da creche nas açóes das crianças pequenas (BOMFIM, 2002, 2006; CAMPOS-DE-CARVALHO, 1990; LEGENDRE, 1983, 1986, 1987; MOREIRA, 1992; MENEGHINI; CAMPOS-DE-CARVALHO, 2003). Desses, somente os estudos de Bomfim analisaram ambientes para crianças com menos de 24 meses de idade. Mais recentemente, pesquisas na área da Educação têm discutido a organização espacial de berçários numa perspectiva histórico-cultural (GUIMARÁES, 2008; MOREIRA, 2011), questionando a seleção de objetos e mobiliários que compóem esses ambientes e a (não) participação dos bebês nesse processo. Estudos na área da Geografia da Infância também têm discutido a produção e transformação dos espaços da creche pelas crianças e como esses sujeitos se constituem nas relaçóes sócio-espaciais (LOPES, 2012).

Ao lado desse cenário, vários documentos têm sido elaborados $\mathrm{e}$ disponibilizados pelo Ministério da Educação com o intuito de orientar as práticas pedagógicas com crianças pequenas, nos quais encontramos uma preocupação com a questão espacial. Dentre eles, destacamos Critérios para um Atendimento em Creches que Respeite os Direitos Fundamentais da Criança (CAMPOS; ROSEMBERG, 1995/2009), Subsídios para Credenciamento $e$ Funcionamento de Instituiçóes de Educação Infantil (BRASIL, 1998b), Referencial Curricular Nacional de Educação Infantil (BRASIL, 1998a), Diretrizes Curriculares Nacionais para a Educação Infantil (BRASIL, 1999), Plano Nacional de Educação (BRASIL, 2001), Parâmetros Básicos de InfraEstrutura para Instituiçóes de Educação Infantil (BRASIL, 2006), Indicadores de Qualidade na Educação Infantil (BRASIL, 2009) e Brinquedos e brincadeiras de Creches (BRASIL, 2012), que norteiam a construção de uma regulamentaçáo da educação infantil e auxiliam na promoção da qualidade dessa modalidade de educação. De modo geral, esses textos concebem os aspectos do ambiente como elementos relevantes para a educação da criança pequena e apresentam orientaçóes relevantes para o planejamento, a organização e o uso dos espaços.

Apesar de todos esses documentos procurarem fornecer suporte técnico-científico aos educadores sobre a questão espacial, ainda é frequente encontrarmos ambientes planejados sem uma reflexão crítica dos educadores acerca das intençóes pedagógicas. Muitas vezes, o planejamento dos ambientes ocorre somente no início do ano, como se esses não se modificassem nas interaçôes cotidianas e fossem iguais para todas as crianças, e tivessem o mesmo significado para crianças e adultos. Por outro lado, é preocupante o fato de os ambientes estarem organizados com base nas orientaçóes sugeridas nos documentos, mas o processo de organização não envolver a participação das crianças e não permitir interaçôes significativas com os objetos e as pessoas. Isto 
denuncia uma pedagogia voltada para a submissão (KUHLMANN JR., 1998), a qual contribui para a dependência das crianças às determinaçóes dos adultos em relação à escolha de brinquedos e locais para brincar, à distribuição espacial, à transformação dos cenários etc. Sabemos que os adultos organizam os ambientes de acordo com suas concepções, crenças e valores acerca da infância e da educação dirigida a ela.

Historicamente, a organização dos berçários de creche tem sido feita com base em modelos de outras instituiçóes que lidam com crianças e infâncias, tais como: a família, a escola, o hospital e o abrigo, sem refletir sobre as especificidades da instituição creche e das capacidades e necessidades dos bebês. Além disso, muitos desses ambientes têm sido improvisados e adaptados para atender, de um lado às demandas das famílias de terem um local para deixar seus pequenos enquanto estão trabalhando, ou para preparar os filhos desde cedo para o ingresso à escola, e, por outro, ao direito de famílias e crianças brasileiras à creche, como dispóe a Constituição Federal de 1988. Por uma razão ou outra, os ambientes de berçário têm se apresentado pouco satisfatórios ao desenvolvimento e à aprendizagem $\mathrm{da}$ criança, seja pela postura escolarizada (cartazes, janelinhas-do-tempo, chamadinhas, ajudantes do dia, quantos somos etc.), seja pela preocupação higienista e assistencial.

$\mathrm{Na}$ maioria das vezes, em nossa cultura, os berçários se configuram em arranjos espaciais abertos ${ }^{3}$ (LEGENDRE, 1983), isto é, sua estruturação espacial é circunscrita aos contornos do ambiente por elementos arquitetônicos (portas e janelas) e não arquitetônicos (mobiliário), com poucos elementos físicos. Esse tipo de configuração espacial reflete a crença de que ambiente seguro é aquele que apresenta o mínimo de objetos e mobiliário (leia-se obstáculos) e o centro vazio oferecendo espaço para a criança poder se movimentar. Paradoxalmente, ao mesmo tempo em que o discurso dos adultos valoriza o movimento, os bebês permanecem um bom tempo do dia em berços ou bebês-conforto. Vários estudos têm demonstrado que ambientes claramente delimitados podem favorecer a organização e o deslocamento dos pequenos no ambiente. Ambientes semi-estruturados em espaços-atividades, como os cantos temáticos, podem auxiliar na apropriaçáo dos espaços pelas crianças com segurança (BRASIL, 2006).

3 O termo Arranjo Espacial foi usado pelo arquiteto Alain Legendre em 1983 para se referir aos aspectos quantitativos e qualitativos em um determinado ambiente, isto é, aos objetos e arquitetura e como esses estão dispostos uns para os outros. O Arranjo Espacial Aberto se constitui numa organização espacial cuja estruturação física está limitada aos contornos do ambiente. 
Este artigo discute os modos como os aspectos físicos dos ambientes para bebês são organizados a partir de um estudo de caso/intervenção num berçário de creche do município do Rio de Janeiro. Foram questóes de estudo: Quais espaços os adultos têm oferecido aos bebês? Qual a participação dos bebês na organização desses ambientes? Como os bebês têm interagido com esses ambientes? Quais estratégias os bebês têm utilizado para se apropriarem desses espaços e os transformarem em lugar? Entendemos que esta pesquisa pode contribuir para ampliar o debate sobre o planejamento e a organizaçáo de ambientes para os bebês em creches, especialmente com diretores, coordenadores e educadores de creche.

\section{Espaço: uma construção social}

De acordo com Miguel e Zamboni (1996), o conceito de espaço é pouco problematizado na educação infantil. Este verbete apresenta várias definições nos dicionários comuns, geralmente relacionadas à ideia de distância, volume, área, configuraçáo arquitetônica e contexto cultural. A variedade de significaçóes nos remete às várias áreas do conhecimento que estudam o tema. No entendimento de Santos e Souza (1986), o espaço é o mais interdisciplinar dos objetos concretos, devendo ser discutido dialogicamente.

Adotamos um olhar plural e histórico-cultural para o espaço pautado nas ideias de Lefebvre, Santos, Vigotski e Wallon. Falamos de espaço geográfico, que traz em seu bojo a dimensão humana. Na formulação do geógrafo Milton Santos (1999), o espaço geográfico é uma invenção humana híbrida, apresentando-se como um composto de formaconteúdo cujo significado só emerge quando a forma (material) e o conteúdo (social) são vistos em conjunto, dialeticamente, formando uma unidade. Isto significa dizer que o espaço náo abrange somente aquilo que é concreto, ou seja, a sua forma; ele se constitui como campo de relaçóes dialéticas, de tensóes e embates permanentes, sendo, portanto, um elemento processual. $\mathrm{O}$ espaço é um sistema interdependente de formas (objetos) e açôes sobre essas (conteúdo), no qual os objetos só podem ser compreendidos na relação com os homens. Nesse sentido, ele não é algo em si mesmo, um elemento externo ou mesmo um produto acabado, mas, ao contrário, ele é aquilo que os sujeitos produzem em relaçóes concretas, circunscritas a um determinado contexto histórico-cultural.

$\mathrm{Na}$ geografia humanista de Yi-Fu Tuan (1980), encontramos uma interessante distinção entre as noçóes de espaço, ambiente e lugar com base no nível de significação atribuído a essas categorias espaciais. A ideia de espaço se refere a sua potencialidade de ser significado por uma cultura que o transforma em ambiente. Este, por sua vez, vivenciado por sujeitos que o 
percebem de modo singular, o transformam em lugar. Dessa forma, não existe espaço neutro nem universal, na medida em que ele está sempre disponível a significaçôes que emergem através das experiências e vivências dos indivíduos.

Seguindo a perspectiva de Santos, no campo da Psicologia, Vigotski (2010) e Wallon (1986) apontam para a necessidade de conceber o espaço numa dimensão dialética, ou seja, espaço e pessoa não se opóem; eles se constituem na relação de interdependência. No texto Quarta aula: a questáo do meio na pedologia, Vigotski (2010) adverte que o meio (espaço/ambiente/ lugar) nunca é estático; ao contrário, ele se modifica em cada momento da vida da criança. Para ela o ambiente é o seu mundo, um contexto de interaçóes que vai ganhando novos sentidos conforme suas experiências cotidianas. Assim,

[...] no começo também se trata de um mundo muito pequeno, o mundo do quarto, o mundo do parque mais próximo, da rua. Com os passeios, seu mundo aumenta e, cada vez mais, novas relaçóes entre a criança e as pessoas que a circundam tornam-se possíveis. [...] Cada idade possui seu próprio meio, organizado para a criança de tal maneira que o meio, no sentido puramente exterior dessa palavra, se modifica para a criança a cada mudança de idade. (VYGOTSKY, 1935/2010, p. 683, grifo nosso).

Do mesmo modo que Vigotski (2010) destaca o caráter relacional e processual do espaço, Wallon (1986) chama a atençáo para a mudança do sentido do meio para a pessoa, dependendo do seu estado afetivo e motivaçóes em cada idade e contexto cultural. Com base nesse argumento, podemos dizer que as crianças sempre estâo ressignificando os espaços que lhes são ofertados, seja aqueles que nós, adultos, qualificamos como adequados e propícios à aprendizagem e ao desenvolvimento, seja aqueles que acreditamos ser precários e inadequados para a infância. $\mathrm{O}$ espaço é sempre um campo de possibilidades onde cada sujeito produz o seu, na medida em que as pessoas constroem sentidos particulares sobre o espaço a partir dos significados que a cultura lhes apresenta. Em outras palavras, o ser humano, ao afetar e ser afetado pelos diferentes ambientes, cria espaços próprios, únicos, singulares e inéditos.

A seguir, apresentamos um recorte da pesquisa original circunscrito ao agrupamento de bebês. Privilegiamos como categoria espacial de análise o arranjo espacial como mediador das práticas pedagógicas e interaçóes dos bebês com os aspectos físicos do ambiente e outras pessoas (bebês e adultos). 


\section{O contexto da pesquisa}

Nosso objetivo foi conhecer os significados do espaço na prática pedagógica dos educadores do Berçário I e os efeitos da pesquisa-intervenção na transformação desse ambiente.

A pesquisa constitui-se num estudo de caso/intervenção e foi conduzida numa creche institucional da cidade do Rio de Janeiro, que atendia a filhos de servidores públicos municipais com idades entre zero e seis anos, em 2008. Funcionava em período integral (das 7 às 19 horas), de segunda a sexta-feira. A instituição possuía três salas de berçários ${ }^{4}$ e quatro de maternal.

Participaram do estudo todos os educadores e todas as crianças do Berçário I 60, ou seja, oito educadores (um homem e sete mulheres ${ }^{5}$ ) e 24 bebês ( 14 meninas e 10 meninos), com idades inicialmente entre 4-16 meses (fevereiro) e 14-24 meses no final (dezembro) da pesquisa de campo.

\section{A produção dos dados}

Em todo o percurso metodológico, procuramos discutir com os educadores as etapas da pesquisa, convidando-os a propor diferentes situaçóes espaciais, as quais seriam, posteriormente, fotografadas e analisadas. Concordamos com Rocha e Aguiar (2003) quando afirmam que as metodologias coletivas aguçam discussóes e possibilitam produçóes conjuntas, fortalecendo os vínculos entre os profissionais e a ideia de instituição como uma unidade indissociável. Essa metodologia nos ofereceu subsídios para apreender questóes relativas à prática e à formação dos educadores, no ambiente de trabalho, a partir do olhar dos próprios sujeitos em diálogo com o nosso olhar. A pesquisa assumiu, assim, um viés colaborativo (SCHAPPER; SILVA, 2010), na medida em que os educadores investigaram as suas próprias açóes, e caracterizou-se como interventiva, visto que a relaçáo do pesquisador com o objeto de estudo orientou os caminhos da pesquisa, tornando-se, portanto, uma produção de todos os sujeitos envolvidos (ROCHA; AGUIAR, 2003).

Nesse sentido, valorizamos a participação ativa dos educadores como copesquisadores e sujeitos da ação (VASCONCELLOS; VALSINER, 1995), ou

4 Desde 2012, a creche possui apenas uma sala de berçário e atende a crianças de zero a cinco anos de idade.

5 Até o mês de setembro, o grupo de educadores do Berçário I era composto somente por mulheres. 
seja, nosso interesse não residiu em realizar uma pesquisa sobre os educadores da creche, mas, sobretudo, com eles. Ao problematizar as práticas habituais, oferecemos a eles outras possibilidades de pensar a realidade e produzir novos sentidos, provocando a reflexão e a busca de respostas possíveis para lidar com as questóes do cotidiano e com aquilo que se encontrava naturalizado pelo senso comum (SCHAPPER; SILVA, 2010).

Elegemos a observação participante, as sessóes reflexivas e a fotografia como métodos e técnicas para a produçẫo dos dados. Os materiais utilizados foram: uma câmera digital, o diário de campo da pesquisadora e o de uma bolsista de iniciação científica.

Os registros observacionais foram coerentes com a referência teórica adotada e com a preocupação de entender as relações das crianças e dos educadores com o espaço/ambiente. Desta forma, eles foram feitos pela pesquisadora e por uma bolsista, durante 30 minutos, nos períodos da manhã e tarde, nas segundas, terças e quintas-feiras, entre os meses de fevereiro e dezembro de 2008. Esses registros preconizaram os arranjos espaciais e as relaçôes que os bebês estabeleciam com os mesmos, bem como as intervenções dos educadores nas suas açóes e nos aspectos físicos do ambiente.

De acordo com Szundy (2005, p. 90), “[...] as sessóes reflexivas são contextos de criação de oportunidades de construção de significados sobre a prática docente em colaboraçáo com um pesquisador externo e se caracterizam como sessóes de discussáo". Aqui, denominamos sessóes reflexivas as discussóes reflexivas que realizamos com os educadores entre os meses de julho a dezembro. Realizamos quatro sessôes reflexivas com o grupo de educadores, nas quais foram abordados os seguintes temas: escolha do brinquedo de grandes dimensões; a utilização dos cestos de vime; a organização dos ambientes; e a transformaçáo dos ambientes da creche (análise de fotos da sala produzidas em 2004, 2006, inserção de 2008 e julho de 2008).

De acordo com Justo e Vasconcelos (2009), a fotografia, como forma de linguagem, tem o intuito de dar visibilidade ao recorte da realidade que o autor selecionou para capturar, construindo sentido para aquilo que até então era despercebido. As fotos datadas de 2008 foram feitas pela pesquisadora durante as atividades livres das crianças com o objetivo de registrar os arranjos espaciais em alguns momentos marcados por transformaçóes nos ambientes, provocadas por esse estudo: a) inserção (fevereiro); b) introdução das almofadas de grandes dimensões (maio); c) festa junina (junho); d) introdução dos cestos de vime (agosto); e) introduçáo dos brinquedos espumados (setembro); e f) retirada de alguns berços da sala e estruturação do chão pela colocação de tapetes emborrachados (novembro). 


\section{Arranjos espaciais no berçário: transformações a partir da reflexão coletiva}

A sala do Berçário I ficava localizada logo após o hall de entrada. Ela possuía duas grandes janelas de vidro que permitiam enxergar todo o ambiente. Também, era a maior sala de atividades, medindo aproximadamente $62 \mathrm{~m}^{2}$.

No início de nossa incursão no campo, o ambiente do Berçário I era formado por treze berços brancos organizados um do lado do outro, ocupando grande parte dos contornos da sala. Pinturas e colagens das crianças sobre desenhos feitos pelas educadoras e painéis estavam afixadas em algumas paredes, na altura das crianças. Um armário branco pequeno ficava encostado na parede que dividia o berçário do fraldário/banheiro, sendo ele o único móvel para as educadoras guardarem o material pedagógico (material de artes e livros de história), os remédios, as cadernetas de anotação e de planejamento pedagógico. Em frente ao armário e encostada na parede perpendicular, havia uma mesa e duas cadeiras de pequenas dimensóes. Do outro lado da sala existia um canto formado por três colchonetes em frente de um grande espelho com uma barra de sustentação, na qual eram presos alguns brinquedos. Este canto era chamado de cantinho da brincadeira. Ao lado, ficavam arrumados os bebês-conforto. No teto, alguns módulos feitos de cartolina pelas educadoras ficavam pendurados sobre a área dos colchonetes e próximos da entrada e dos berços (Figura 1). O chão era minimamente estruturado por alguns brinquedos deixados pelas crianças e um tapete de diferentes texturas que era colocado para a realização de atividades dirigidas.

Figura 1 - Sala do Berçário I 60: localização dos móbiles e berços

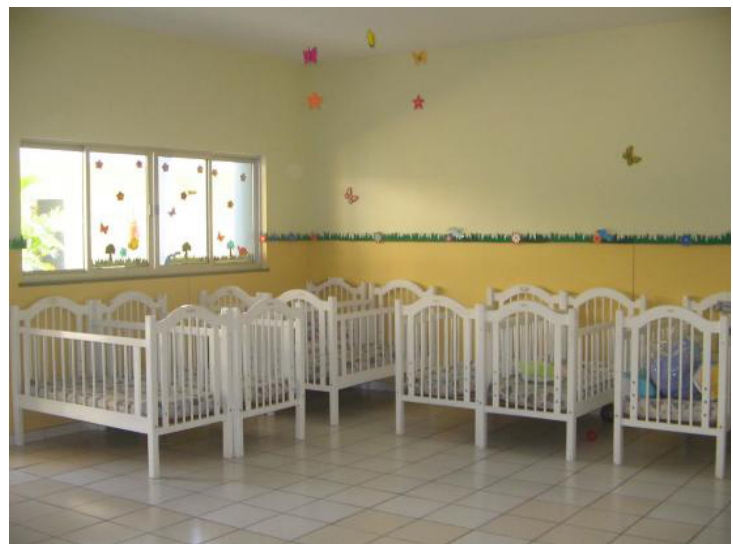

Fonte: a própria autora (fev. 2008). 
Como podemos notar, o arranjo espacial original do Berçário I caracterizava-se por um espaço central vazio e os contornos estruturados por mobílias e objetos. Essa organizaçâo espacial, que é frequente em berçários, parece estar de acordo com a crença de que criança pequena precisa de espaço devendo o ambiente ter o mínimo possível de objetos e mobílias, principalmente no centro da sala, para evitar que elas, as crianças, se machuquem. Dessa forma, para as educadoras, ambiente vazio significava espaço seguro.

No entanto, podíamos notar a presença de algumas zonas circunscritas (ZC) (áreas delimitadas no mínimo em três lados, por barreiras estruturadas por mobiliário, parede, desnível de solo etc.), como o cantinho da brincadeira, e os espaços formados entre os berços e debaixo da mesa. Esses espaços eram bastante procurados pelas crianças, além da zona do adulto (ZA). De acordo com Legendre (1986), as ZC se constituem em áreas de alta estruturação espacial, favorecendo a ocorrência de interaçóes intensas e duradouras entre crianças pequenas e sua autonomia. As ZC permitem às crianças acesso visual aos educadores, pois, o comportamento de apego, que é típico em crianças nos primeiros anos de vida (AINSWORTH, 1963), faz com que elas necessitem do contato visual com os adultos.

A ideia de ZC parece se apresentar como uma alternativa para o planejamento de ambientes simultaneamente desafiadores e seguros, sem que a criança precise estar em volta do adulto. Entendemos que um ambiente seguro é aquele no e com o qual a criança pode contar para se arriscar a ter experiências outras, diferentes e criativas.

Apesar de as ZC fornecerem suporte para a ocorrência de brincadeiras e exploraçóes, nem todas essas áreas eram valorizadas pelas educadoras, como revelam os registros de algumas falas: Andreas sai debaixo da mesa. Aí náo é lugar de brincar! $\mathrm{Ou}$ Penélope sai dai [entre os berços]. Vai brincar lá com os brinquedos! [apontando para o canto da brincadeira].

Para aquelas educadoras, a sala estava claramente dividida em espaços e momentos de cuidado e brincadeira. Por exemplo, o local destinado à brincadeira era o canto da brincadeira e ao descanso, os berços. Os demais locais eram definidos em função das ações/atividades dos bebês: a realização de trabalhinhos (mesa), a alimentação (bebêsconforto arranjados em semicírculo, próximos da mesa nos horários de refeição), o deslocamento dos bebês (o centro da sala vazio) e a contaçáo de histórias ou atividade dirigida (adulto no centro da sala, rodeado pelos bebês).

Ao longo do estudo, fomos problematizando com os educadores os espaços e os tempos de brincar e refletindo sobre as relaçôes estabelecidas entre os bebês e os espaços, além das possibilidades de construção de outros significados. Desse modo, os educadores foram desnaturalizando a ideia de que um centro da sala precisava estar vazio, e começaram a pensar em algumas possibilidades de estruturação dessa área, tais como a colocação de brinquedos de grandes dimensóes, tapetes emborrachados e fotos coladas no chão. Igualmente, os berços e os bebês-conforto foram se constituindo em 
lugares simultaneamente de brincadeira e cuidado, na medida em que os educadores perceberam que um aspecto não exclui o outro. Assim, os educadores passaram a oferecer aos bebês brinquedos de pequenas dimensôes quando eles estavam nos berços ou bebês-conforto e a brincar com eles no momento da troca de fralda, alimentaçáo etc.

\section{Transformações espaciais}

Nossa primeira intervenção foi oferecer aos educadores duas almofadas temáticas (joaninha e porco ${ }^{6}$ ) para que eles as integrassem no ambiente. Como resultado, os bebês utilizaram as almofadas como estruturadores móveis, deslocando-os de cima dos colchonetes e das áreas próximas das paredes (onde eram geralmente colocadas pelos educadores) para outras áreas da sala, como o centro da sala. As almofadas propiciaram a exploração e a permanência das crianças em áreas de baixa definiçâo espacial, como a zona 0 (zonas de circulaçáo interna) (LEGENDRE, 1987), que abrange os espaços vazios da sala.

Em junho, uma significativa mudança espacial foi realizada no Berçário I, como mostra a Figura 2: bandeirinhas e cordóes de folhas de revista feitos pelos educadores foram presos no teto; os berços foram divididos em dois grupos, formando uma zona circunscrita. Três berços foram utilizados para guardar brinquedos, livros e pertences dos educadores. Também, o painel de figuras humanas foi substituído por um painel com as fotos das crianças e suas famílias.

Figura 2 - Cordões feitos de revista no teto e painel com fotos das famílias dos bebês

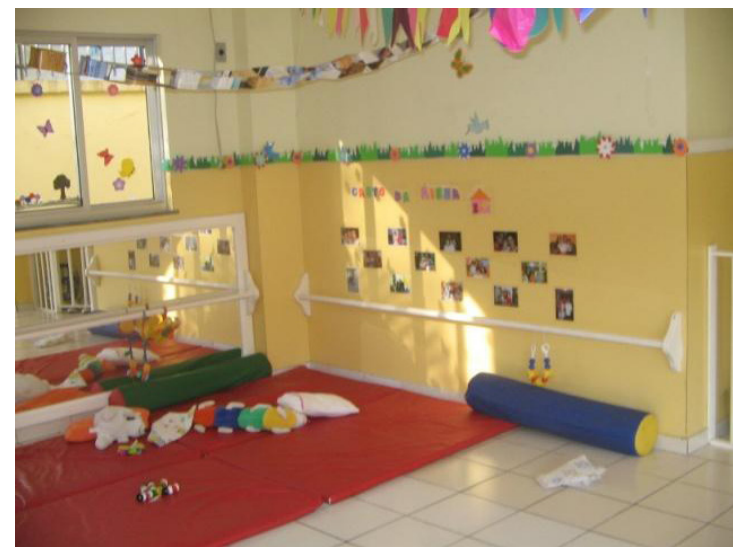

Fonte: a própria autora. (jun. 2008).

6 Esses animais foram selecionados pela equipe de pesquisa por aparecerem recorrentemente nas músicas e histórias. 
Percebemos a sensibilidade dos educadores em retirar o painel de figuras humanas e de substituí-lo por outro com fotos das famílias, chamando a atenção das crianças. Para a produção do novo painel, os educadores solicitaram às famílias as fotos, o que, de alguma forma, nos pareceu ser um movimento interessante de aproximação entre as duas instituições. Tendo em vista que a família é considerada o porto seguro das crianças (MINUCHIN, 1982), a criação deste painel ofereceu suporte afetivo para melhor exploração e apropriaçáo do ambiente pelos bebês.

Realizamos a primeira sessão reflexiva para discutir possibilidades de ampliar o grau de estruturação da sala. Levamos encartes de brinquedos de grandes dimensóes para crianças pequenas e os entregamos ao grupo. As educadoras selecionaram alguns brinquedos, os quais avaliaram ser interessantes para os bebês por propiciarem várias formas de exploraçáo sensorial e de movimentos. Elas escolheram dois brinquedos espumados de grandes dimensóes, formados por módulos. Após algumas reflexóes sobre as possibilidades de uso dos brinquedos, as educadoras perceberam que eles poderiam favorecer a interaçáo dos bebês ao serem arranjados de modo a delimitarem zonas circunscritas, deixando-as mais livres para atender àqueles que precisassem de sua ajuda.

A questáo da organização do ambiente para a criança nos remete a outra questáo complementar, qual seja, a problemática do ambiente para o educador. De acordo com Barbosa e Horn (2001, p. 74), o trabalho pedagógico “[...] deve ter como meta a co-habitação [...]" onde as necessidades de crianças e adultos precisam ser respeitadas. $\mathrm{Na}$ sessão reflexiva anterior, as educadoras relataram a necessidade de terem um lugar específico para organizar seus próprios materiais de trabalho, pois o armário era muito pequeno e precário.

$\mathrm{Na}$ tentativa de levá-las a refletir sobre os seus próprios espaços, entregamos ao grupo um conjunto com sete cestos de vime de diferentes tamanhos (quatro com tampa e três sem tampa), e depois discutimos as possibilidades de uso que elas criaram na segunda sessão reflexiva. De modo geral, as educadoras usaram os cestos para guardar diferentes objetos, de acordo com a sua função. A partir da introdução desses objetos, algumas mudanças no ambiente puderam ser verificadas: três cestos foram colocados em cima da mesa e outro menor, em cima do armário, que foi deslocado para a parede ao lado, ficando embaixo da janela e ao lado da mesa. Um cesto sem tampa foi utilizado para guardar brinquedos pequenos e foi colocado dentro de um berço que continha outros brinquedos. O restante dos cestos ficou em um berço para ser utilizado posteriormente. $\mathrm{O}$ fato de as educadoras alterarem a posição do armário para perto da mesa talvez reflita o desejo de ampliá-lo para melhor organizar o material de trabalho. Neste caso, a mesa e os cestos funcionaram como um anexo do armário. 
Vimos que a introdução de um novo elemento na sala provocou mudanças de relaçóes entre pessoas e delas com os outros objetos. Recuperando as ideias de Santos (1997) sobre a dialética entre a configuração territorial ou geográfica e a dinâmica social, esta nova configuração do ambiente reforçou a potência da zona circunscrita formada pela mesa encostada na parede, visto que o fechamento de mais um lado foi materializado com a lateral do armário. Se, anteriormente, esta área já era utilizada pelas crianças, agora, ela ampliava as possibilidades não só de procura pelo local, mas, sobretudo, de sua permanência nele.

Seguindo a ideia das almofadas temáticas e dos brinquedos espumados, que ainda não tinham sido introduzidos no ambiente, as educadoras levaram para a sala alguns blocos de espuma de grandes dimensóes, que estavam numa sala de crianças maiores, e incentivaram os bebês a brincarem de modos diversos, no centro da sala.

Outro aspecto interessante, fruto de nossas discussóes, foi a confecção de alguns brinquedos pelas educadoras usando garrafas pet com tintas coloridas, que foram espalhadas pela sala, convidando os bebês a engatinharem ou caminharem na sua direção. Percebemos que os brinquedos começaram a ser organizados em áreas anteriormente vazias, ocupando principalmente a área central. Essa transformação espacial provocou a distribuição mais equilibrada das crianças pela sala, além de serem observados deslocamentos mais interessantes, como apresentamos nas notas de campo de 25 ago. 2008:

- I. andava por toda a sala, apontando para todos os móveis, brinquedos e figuras nas paredes; falava muito cada vez que apontava para algum lugar.

- M. andou por toda a sala e náo procurava a presença de nenhum adulto, também não procurava a presença de nenhuma outra criança. A menina brincou com o andador, até que descobriu que podia ficar entre o armário do material das educadoras e a parede.

- M. S. tirava os bebês conforto e os arrastava por todo o espaço. I., A. J., M. So. e N. imitaram a amiga, e logo os objetos estavam espalhados por toda a sala; eles se sentavam $e$ imitavam as educadoras, sacudindo o bebê conforto como se ninassem uns aos outros.

No primeiro registro vimos que a estruturação do ambiente através do mobiliário, dos brinquedos e painéis, além de favorecer a exploração de diferentes áreas do ambiente, propiciou jogos de linguagem, isto é, o exercício da oralidade e do pensamento. 
Durante o dia de Centro de Estudos realizamos a terceira sessão reflexiva, que abordou a questáo do arranjo espacial da sala. Pedimos que o grupo representasse graficamente como a sala estava organizada e que explicasse a localização dos elementos espaciais (mobiliário, brinquedos e demais objetos). De modo geral, as educadoras preencheram os contornos das salas, estruturados, e deixaram o centro vazio, por acreditarem que a criança pequena precisa de espaço para se movimentar, e que esse deve estar seguro. Explicaram que os berços foram organizados um do lado do outro, junto às paredes, para oferecer espaço amplo no centro da sala para as crianças poderem brincar e se locomover melhor. Os colchonetes foram arrumados próximos do espelho, para propiciar às crianças brincadeiras com a sua imagem e com a dos adultos. Discutimos o que seria, então, um espaço seguro, e se não poderíamos conciliar segurança com desafio. Questionamos o quão seria interessante inserir alguns elementos espaciais no centro da sala para que as crianças tivessem desafios seguros naquela área, como tapetes emborrachados. Esta proposta possibilitou que as educadoras pensassem o arranjo espacial que tinham construído, favorecendo o planejamento de outros mais interessantes à prática pedagógica.

A inserção dos brinquedos de grandes dimensóes na sala ocorreu em quatro etapas consecutivas: a) A utilização dos brinquedos como um só - o Brinquedão - montados sobre o chão; b) A utilização dos brinquedos em módulos separados; c) A utilizaçáo do Brinquedão montado sobre os colchonetes; e d) A utilizaçáo do Brinquedão montado sobre um tapete emborrachado. Esse processo, no entanto, náo ocorreu isento de conflitos, tensóes e insegurança por parte dos adultos (educadoras e pesquisadora) e bebês.

A introdução de brinquedos coloridos, cheios de desafios e de possibilidades de brincadeiras e estruturadores do espaço chamou logo a atenção dos bebês, como geralmente acontece quando apresentamos uma novidade. As educadoras, no entanto, ficaram preocupadas que o contato dos bebês com os brinquedos pudesse trazer consequências negativas, pois, todos queriam brincar com o Brinquedão ao mesmo tempo. Isto deixou o grupo de educadoras tenso, fazendo com que elas permanecessem o tempo todo por perto dos bebês, e direcionando suas açóes na tentativa de evitar conflitos e machucados, seja por mordidas ou quedas. Durante alguns dias, elas se recusaram a montar o Brinquedão e justificavam a decisão dizendo que ele era perigoso para os bebês. Então, elas resolveram desmontar o Brinquedão e arrumá-lo em módulos separados. Como consequência, os bebês brincaram mais sentados, explorando o zíper dos módulos, empilhando-os e arrastando-os.

Conversamos com as educadoras a respeito da extinçáo do Brinquedão, que, afinal, tinha sido criado pelo grupo, e, juntas, encontramos uma solução de recuperá-lo: montar o Brinquedão sobre os colchonetes. Isto fez com que elas 
ficassem mais tranquilas temporariamente, pois ao se deslocar os colchonetes do canto da brincadeira para dar suporte ao Brinquedão, a área ficara desfalcada. Então, elas lembraram que havia módulos de tapete emborrachado guardados no almoxarifado. Eles foram arrumados como base para o Brinquedão e as educadoras se sentiram mais seguras de seu uso pelos bebês (Figura 3).

\section{Figura 3 - Bebês brincando com o Brinquedão armado sobre o tapete emborrachado}

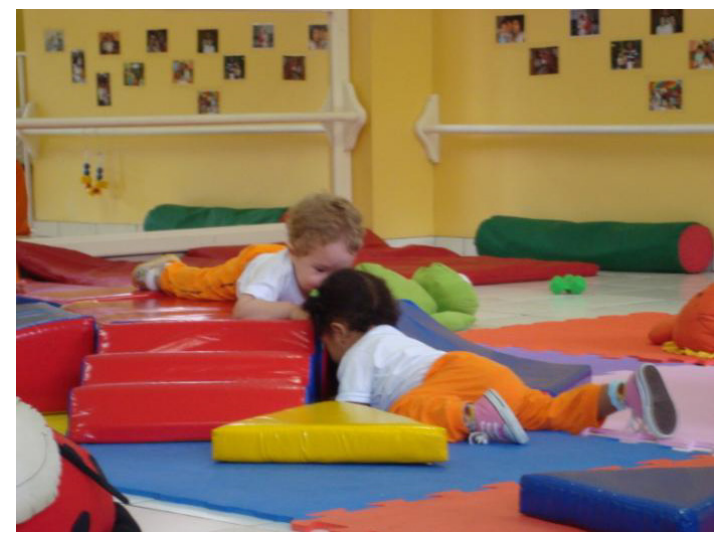

Fonte: a própria autora (set. 2008).

De fato, os bebês brincaram mais livremente quando o brinquedo se encontrava armado sobre uma superfície macia. Podemos dizer que este é um bom exemplo de se organizar um ambiente seguro e desafiador no e com o qual crianças pequenas possam agir autonomamente.

No início do mês de outubro, mais da metade dos educadores saíram da creche por razão do convênio. No Berçário I somente uma educadora permaneceu e um educador foi introduzido no grupo. A mudança no ambiente social provocou alteraçóes também no ambiente físico, especialmente a retirada de vários berços da sala e o rearranjo dos cinco que lá restaram, que assumiram novas funçôes: um foi destinado a guardar as mochilas dos bebês; outros dois se transformaram em trocadores de fralda; e os dois últimos foram usados para guardar os brinquedos e as bolsas dos educadores. A quantidade de bebêsconforto também foi diminuída e eles foram arrumados entre os berços.

Além dessas mudanças, novos objetos passaram a compor o ambiente, como foi o caso do tapete emborrachado e de uma piscina inflável, doada à creche por uma máe. $\mathrm{O}$ tapete era arrumado de diferentes formas e em diferentes locais da sala, mas, geralmente, ele ficava encostado em paredes. A piscina era colocada no centro, mas os bebês levavam-na para outras áreas. Por ser um brinquedo leve, ele 
favorecia o seu deslocamento por crianças muito pequenas sem lhes causar perigo.

Dando continuidade ao registro fotográfico, inicialmente proposto pela pesquisadora, os educadores fotografaram os bebês em momentos diferentes do dia e prenderam as fotos no chão, dando um novo sentido àquele local. Desse modo, os bebês podiam tocar nas fotos não só com as mãos, como faziam no painel, mas também com os pés ou outras partes do corpo, apropriando-se desse espaço.

$\mathrm{Na}$ última sessão reflexiva, apresentamos para o grupo de educadores várias fotos das salas dos berçários da creche em períodos diversos: a) 2004 (fundação da creche); b) 2006 (entrada do grupo de pesquisa na creche); c) 2008 (inserção) e 2008 (julho). Pedimos aos educadores para analisarem as fotos enfocando as transformaçóes físicas dos ambientes e relacionando-as às práticas educativas na creche.

Em relação às fotos que foram feitas em 2004, eles destacaram a escassez de brinquedos e mobílias nas salas dos berçários, comparando esses ambientes com depósito de crianças. Para eles, as fotos transmitiam tristeza e ausência de proposta pedagógica, pois as paredes estavam sem nenhum estímulo para as crianças (figuras, desenhos, trabalhinhos etc.). Percebemos que a intencionalidade pedagógica estava associada à escolarização precoce das crianças, preparandoas para o ingresso na escola. Os educadores ficaram impressionados com o uso coletivo dos colchóes que, para eles, significava desprezo pela individualidade de cada criança. As fotos de 2006 foram percebidas pelos educadores como um avanço da creche em relação à estruturação espacial dos berçários, pois as paredes já apresentavam enfeites e cada criança tinha o seu colchonete para descansar. Também, os educadores destacaram a presença de brinquedos e mobiliário para guardar o material pedagógico (ainda que em condiçôes precárias). Para eles, o desenho feito pelas crianças, preso no armário, na altura delas, expressava a preocupação dos educadores em marcar a creche como um espaço de educação. Os ambientes apresentados nas fotos da inserção de 2008 foram elogiados, porque refletiam a sensação de acolhimento e aconchego, fundamentais para receber as crianças novas e suas famílias. Contudo, os educadores perceberam que as salas ainda não estavam com a cara das crianças, pois os painéis eram produçáo exclusiva dos adultos. Discutimos o quanto é importante estar atento às crianças reais, isto é, com as quais trabalhamos, pois elas precisam ser reconhecidas como coconstrutoras dos ambientes que frequentam. Por fim, os educadores relacionaram as transformações dos ambientes, que aparecem nas fotos feitas em julho de 2008, aos efeitos de nosso estudo, ou seja, as mudanças foram percebidas como fruto de um novo olhar deles sobre o espaço o qual a pesquisa lhes tinha proporcionado. Eles também relataram que se sentiam mais fortalecidos e confiantes para organizar os ambientes de trabalho. 
Concordamos com os educadores quando eles disseram que as primeiras fotos, as de 2004, expressavam a tendência assistencialista de atendimento às crianças pequenas, sendo a creche vista como um lugar destinado exclusivamente para guardálas (CIVILETTI, 1988), ou que refletia a pedagogia da submissão (KUHLMANN JR., 1998). Já as fotos de 2006 apresentavam alguns elementos pedagógicos, refletindo a tendência educacional da creche, apesar de apresentar marcas do modelo escolar. Se compararmos as fotos produzidas em $2006 \mathrm{com}$ as de 2008, verificamos que a creche estava procurando articular o cuidado com a educação, como orientam os documentos citados anteriormente. Embora várias transformaçóes espaciais tenham ocorrido entre os anos de 2006 e 2008, os problemas com a mobília danificada e a pouca quantidade de brinquedos ainda era presente.

\section{Considerações finais}

Esta pesquisa investigou os modos como os aspectos físicos do ambiente do Berçário I foram organizados e modificados pelos educadores a partir de intervençóes realizadas na formação em serviço. Apostamos numa pesquisa-intervenção que convida o educador a ser afetado e a refletir sobre as crenças e os valores que norteiam seu fazer cotidiano. Acreditamos numa pesquisa que possibilite aos educadores que experiências criadoras de organização espacial possam emergir.

Privilegiamos a análise de fotografias e registros em diário de bordo dos arranjos espaciais construídos e reconstruídos, bem como as sessóes reflexivas, que possibilitaram aos educadores revisitarem suas práticas e crenças pedagógicas com crianças ainda muito pequenas, a partir de um outro lugar, qual seja, o de copesquisadores. Buscamos criar uma ambiência de reflexão sobre os arranjos espaciais pensados pelos adultos, analisando o quanto eles são distantes da realidade dos bebês concretos e próximos do modelo escolar.

Iniciamos este artigo discutindo o caráter interdisciplinar do espaço e, junto a isso, a presença de múltiplas possibilidades de interpretá-lo. Neste diálogo com diferentes campos do saber, escolhemos um lugar para direcionar nosso olhar: o referencial teórico da perspectiva histórico-cultural (LEFEBVRE, 1998; VYGOTSKY, 1988; SANTOS, 1999). A partir dele, podemos afirmar que todo ambiente é histórico e simbolicamente construído, e que carrega consigo significados produzidos por uma sociedade que tem concepçóes e expectativas próprias. Sendo o espaço um elemento simbólico, sempre construído na relação dialética entre o homem e o meio, ele só pode ser transformado em lugar quando é ressignificado por cada sujeito. Ou seja, para que o ambiente, que é construído social e culturalmente, ganhe os contornos de lugar, ele precisa ser apropriado, afetado por sujeitos concretos. Nesse sentido, a ideia 
de apropriação está muito próxima à de lugar (TUAN, 1983), que destaca a dimensão afetiva do espaço/ambiente ao ser significado pelos sujeitos.

A creche, como ambiente de promoçáo do desenvolvimento das capacidades infantis, precisa ser constantemente (re)apropriada pelos adultos (educadores) e crianças. Isto significa pensar em ambientes que convidem sempre a modificaçôes, como resultado de uma intencionalidade pedagógica que, por sua vez, é resultante de observaçóes constantes dos desejos, das escolhas e preferências das crianças. Questionamos juntos com os educadores os arranjos espaciais existentes, buscando desnaturalizar as crenças e ideias pré-concebidas sobre o espaço e os objetos, apontando o quáo é importante observar as crianças antes de qualquer proposta de organização do ambiente.

Esperamos que este artigo auxilie educadores e gestores no momento de planejamento e organização de ambientes para bebês em creches e contribua para a melhoria da qualidade da educação infantil.

\section{Referências}

AINSWORTH, M. The development of infant-mother interaction among Ganda. In: FOSS, B. M. (Org.). Determinants of infant behavior. New York: Wiley, 1963. p. 67-104.

BARBOSA, M. C. S.; HORN, M. G. S. Organização do espaço e do tempo na escola infantil. In: CRAIDY, C.; KAERCHER, G. E. (Org.). Educação infantil: pra que te quero? Porto Alegre: ArtMed, 2001. p. 67-79.

BOMFIM, J. Arranjos espaciais e ocupaçáo do espaço por crianças de 1-2 e 3-4 anos em creches. Dissertação (Mestrado em Psicologia)- Instituto de Psicologia. Universidade de São Paulo, USP, Ribeirão Preto, 2002.

. Trocas sociais de crianças de 1-2 anos e arranjos espaciais em creches. Tese (Doutorado em Psicologia)- Instituto de Psicologia. Universidade de São Paulo, USP, Ribeirão Preto, 2006.

BRASIL. Ministério da Educação e do Desporto. Conselho Nacional de Educação. Câmara de Educação Básica. Resoluçáo CEB no 01, de 07 de abril de 1999. Institui as Diretrizes Curriculares Nacionais para a Educação Infantil. Brasília, DF: D.O.U., 13 abr. 1999.

- Ministério da Educação e do Desporto. Secretaria de Educação Fundamental. Referencial curricular nacional de educaçáo infantil. Brasília, DF: MEC/SEF, 1998a. 3 v. 
Ministério da Educação e do Desporto. Secretaria de Educação Fundamental. Subsídios para credenciamento e funcionamento de instituiçóes de educaçáo infantil. (v. 1) Brasília, DF: MEC/SEF, 1998b.

. Ministério da Educação. Secretaria de Educação Básica. Brinquedos e Brincadeiras de Creches. Manual de Orientação Pedagógica. Brasília, DF: MEC/UNICEF, 2012.

. Ministério da Educação. Secretaria de Educação Básica. Indicadores da Qualidade na Educaçáo Infantil. Brasília, DF: MEC/SEB, 2009.

- Ministério da Educação. Secretaria de Educação Básica. Parâmetros básicos de infra-estrutura para instituiçóes de educação infantil. Brasília, DF: MEC/SEB, 2006.

. Presidência da República. Casa Civil. Subchefia para Assuntos Jurídicos. Lei $\mathbf{n}^{\circ}$ 10.172, de 9 de janeiro de 2001. Aprova o Plano Nacional de Educação e dá outras providências. Brasília, DF: D.O.U., 10 jan. 2001. Disponível em: <http://portal.mec.gov.br/arquivos/pdf/pne.pdf>. Acesso em: 22 set. 2006.

CAMPOS, M. M.; ROSEMBERG, F. Critérios para um atendimento em creches que respeite os direitos fundamentais da criança. Brasília, DF: MEC/SEF/COEDI, 1995/2009.

CAMPOS-DE-CARVALHO, M. I. Arranjo espacial e distribuiçáo de crianças de $\mathbf{2 - 3}$ anos pela área de atividades livres em creche. Tese (Doutorado em Psicologia)- Instituto de Psicologia, Universidade de São Paulo, USP, Ribeirão Preto, 1990.

CIVILETTI, M. V. P. A creche e o nascimento da nova maternidade. Dissertação (Mestrado em Psicologia Social)-. Fundação Getúlio Vargas, FGV, Rio de Janeiro, 1988.

GUIMARÁES, D. O. Relaçóes entre adultos e crianças no berçário de uma creche pública na Cidade do Rio de Janeiro: técnicas corporais, responsividade, cuidado. Tese (Doutorado em Educação)- Pontifícia Universidade Católica, PUC, Rio de Janeiro, 2008.

JUSTO, J. S.; VASCONCELOS, M. S. Pensando a fotografia na pesquisa qualitativa em psicologia. Estudos e Pesquisas em Psicologia, Rio de Janeiro, v. 9, n. 3, p. 760-774, 20 semestre de 2009.

KUHLMANN JR., M. Infância e educaçáo infantil: uma abordagem histórica. Porto Alegre: Mediação, 1998. 
LEFEBVRE, H. The production of space. Oxford: Blackwell, 1998.

LEGENDRE. A. Approprriation par lês enfants de l'environnement architectural. Enfance, Paris, n. 3, p. 389-395, 1983.

. Effect de transformations de l'espace d'activites sur les echanges sociaux de jeunes enfants o creche. Psicologie Française, Paris, v. 32, n. 1/2, p. 31-43, 1987.

. The effects of environmentally modulated visual accessibility to caregivers on early interactins. International Journal of Behavioral Development, Utrecht, v. 18 , n. 32 , p. 297-313, 1995.

Effects of spatial arrangements on child/child and child/arrigivers interactions: an ecologiacal experiment in day care centers. In: Reunião Anual de Psicologia da Sociedade de Psicologia de Ribeirão Preto, 16, 1986, Ribeirão Preto, Anais... p. 131-142, 146, Ribeirão Preto, 1986.

LOPES, J. J. M. Os bebês, as crianças pequenas e suas condiçôes históricogeográficas: algumas notas para debate teórico-metodológico. Educação em foco. Edição especial, Juiz de Fora, p. 151-161, ago. 2012.

MENEGHINI, R; CAMPOS-DE-CARVALHO, M. I. Arranjo espacial na creche: espaços para interagir, brincar isoladamente, dirigir-se socialmente e observar o outro. Psicologia: Reflexão e Crítica. v. 16, n. 2, p. 367-378, 2003.

MIGUEL, A.; ZAMBONI, E. (Org.). Representaçóes do espaço: multidisciplinaridade na educação. Campinas: Autores Associados, 1996.

MINUCHIN, S. Família, Funcionamento e Tratamento. 2. ed. Porto Alegre: Artmed, 1982.

MOREIRA, A. R. C. P. Transformaçóes espaciais e interaçáo social entre crianças de dois anos de idade - uma proposta educacional para a creche. Dissertaçáo (Mestrado em Psicologia Social)- Instituto de Psicologia, Universidade Gama Filho, UGF, Rio de Janeiro, 1992.

. Ambientes da infância e a formaçáo do educador: arranjo espacial no berçário. Tese (Doutorado em Educação)- Faculdade de Educação. Universidade do Estado do Rio de Janeiro, UERJ, Rio de Janeiro, 2011.

RIO DE JANEIRO. Secretaria Municipal de Educação. Portaria no 20 E/EDG, de 18 de novembro de 2003. Rio de Janeiro: Diário Oficial, 18 nov. 2003.

ROCHA, M.; AGUIAR, K. Pesquisa-intervenção e a produção de novas análises. Psicologia, Ciência e Profissáo, Brasília, DF, v. 23, n. 4, p. 64-73, 2003. 
SANTOS, M. Metamorfoses do espaço habitado. 5. ed. São Paulo: Hucitec, 1997.

. O espaço geográfico, um híbrido. In:

A natureza do espaço: técnica e tempo. Razão e emoção. 3. ed. São Paulo: Hucitec, 1999. p. 72-88.

SANTOS, M.; SOUZA, M. A. (Org.). O espaço interdisciplinar. São Paulo: Nobel, 1986.

SCHAPPER, I.; SILVA, L. S. P. Ação colaborativa na creche: compartilhando sentidos e significados. In: SILVA, L. S. P; LOPES, J. J. M. (Org.). Diálogos de pesquisa sobre crianças e infâncias. Niterói: Editora da UFF, 2010. p. 61-68.

SZUNDY, P. T. C. A construçáo do conhecimento no jogo e sobre o jogo. Ensino-aprendizagem de LE e formaçáo reflexiva. Tese (Doutorado em Linguística Aplicada e Estudos da Linguagem)- Pontifícia Universidade Católica, PUC/SP, São Paulo, 2005.

TUAN, Y-FU. Espaço e lugar. São Paulo: Difel, 1983.

Topofilia - um estudo da percepção, atitudes e valores do meio ambiente. São Paulo: Difel, 1980.

VASCONCELLOS, V. M. R.; VALSINER, J. Perspectiva Co-Construtivista na Psicologia e na Educaçáo. Porto Alegre: Artes Médicas, 1995.

VYGOTSKY, L. S. A formaçáo social da mente. São Paulo: Martins Fontes, 1988.

Quarta aula: a questão do meio na pedologia. Psicologia USP, Tradução de Márcia Pileggi Vinha, São Paulo, v. 21, n. 4, p. 681-701, 2010.

WALLON, H. Os meios, os grupos e a psicogênese da criança. In: WEREBE, M. J. G.; NADEL-BRULFERT, J. (Org.). Henri Wallon. Tradução de Elvira Souza Lima. São Paulo: Ática, 1986. p. 168-178. 